\title{
New Integrated Data Analyses Software Components
}

\author{
by Ronald Conze, Frank Krysiak, Josh Reed, Yu-Chung Chen, Hans-Joachim \\ Wallrabe-Adams, Colin Graham and the New Jersey Shallow Shelf Science Team, \\ Volker Wennrich and the Lake El'gygytgyn Science Team
}

doi:10.2204/iodp.sd.9.08.2010

\section{Introduction}

Data management in scientific drilling programs such as the Integrated Ocean Drilling Program (IODP), the International Continental Scientific Drilling Program (ICDP), and the Antarctic Drilling Program (ANDRILL) performs two functions: firstly, the capture of drilling and scientific data during an expedition, and secondly, the long-term storage and dissemination of these data. Here we describe the progress in linking data management with stand-alone data capture and visualization applications. This provides a two-way flow of data between the database and the applications, and a more integrated data environment for scientists. The new system has been tested, so far, with cores from the IODP Expedition 313 New Jersey Shallow Shelf and the ICDP Lake El'gygytgyn Drilling Project.

\section{The Components}

1. The Expedition Drilling Information System (ExpeditionDIS) is used for ICDP lake drilling projects and IODP-MSP expeditions in a two-phase data capture process, at the drill site during the drilling operation and in one or more laboratories during the post-drilling phase (Conze et al., 2007). It is based on a relational database using mainly digital forms for the data input.

2. PSICAT, the Paleontological Stratigraphic Interval Construction and Analysis Tool, is a stand-alone, Java-based graphical editing tool for creating and viewing core description diagrams (http://dev.psicat.org/) that can be used in the field as well as in a laboratory environment.

3. Corelyzer as part of CoreWall (http:// www.corewall.org/) is a scalable, extensible visualization tool, developed to enhance the study of geological cores. The strength of Corelyzer is the ability to display large sets of core imagery, with multi-sensor logs and annotations. Plugins can be developed to provide additional data visualization functionality.

4. Correlator, another CoreWall product, is an interactive workstation software product for displaying and depth-shifting/merging data from multiple cores and/or downhole geophysical logging data.

\section{The Concept}

The idea is to combine the advantages of all these stand-alone tools into an interoperable configuration.

The link between the ExpeditionDIS, PSICAT, and Corelyzer is realized by a Common Exchange Format (Fig. 1) using XML notation. The general workflow starts with the export of all relevant primary data for core recovered from a drill hole from the ExpeditionDIS in the Common Exchange Format, which can then subsequently be imported by PSICAT and/or Corelyzer. A Common Exchange Format file contains the corresponding driller depths and file paths for core section images as well as any existing lithological visual core description data for each core section, and other corresponding data sets such as petrophysical (e.g., from Multi Sensor Core Logging, MSCL) data.

1. By importing the ExpeditionDIS data as Common Exchange Format, PSICAT generates a visual core description (VCD) form for each core section. Existing VCD data can be modified, and new data can be added using the graphical functionality of PSICAT. The new or modified data can be written back to the

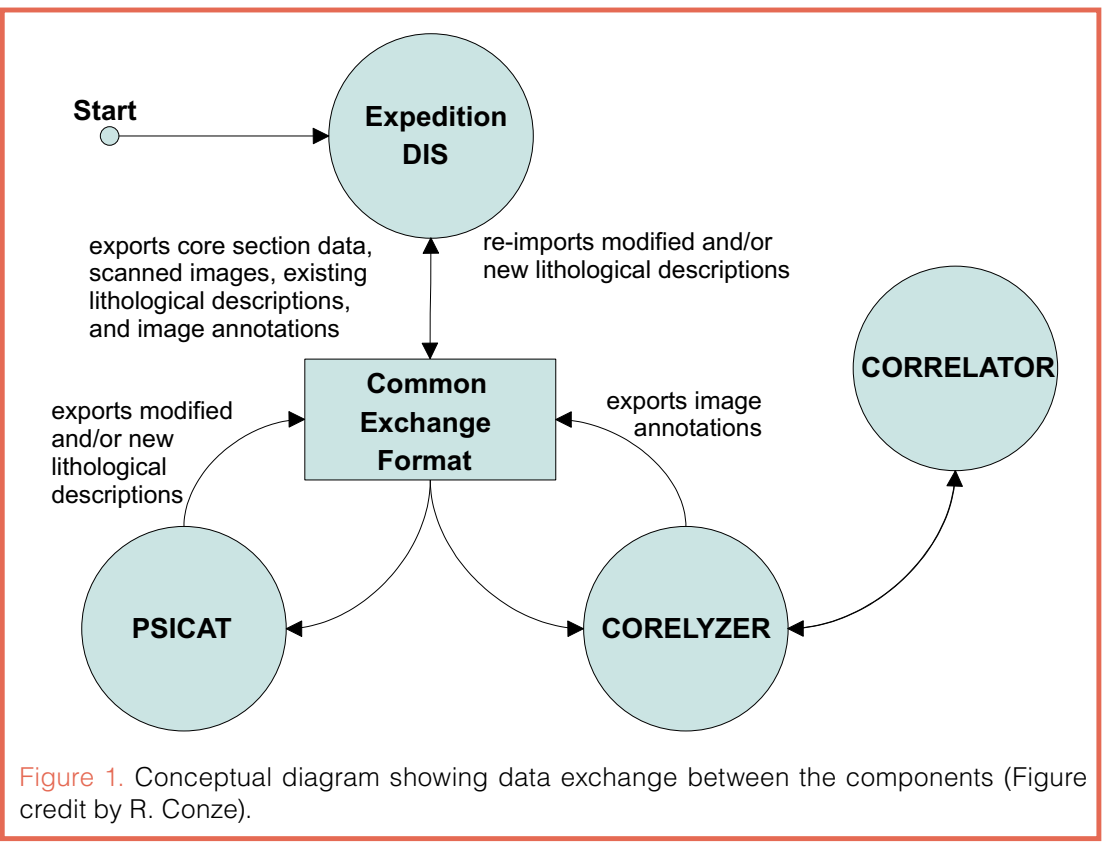




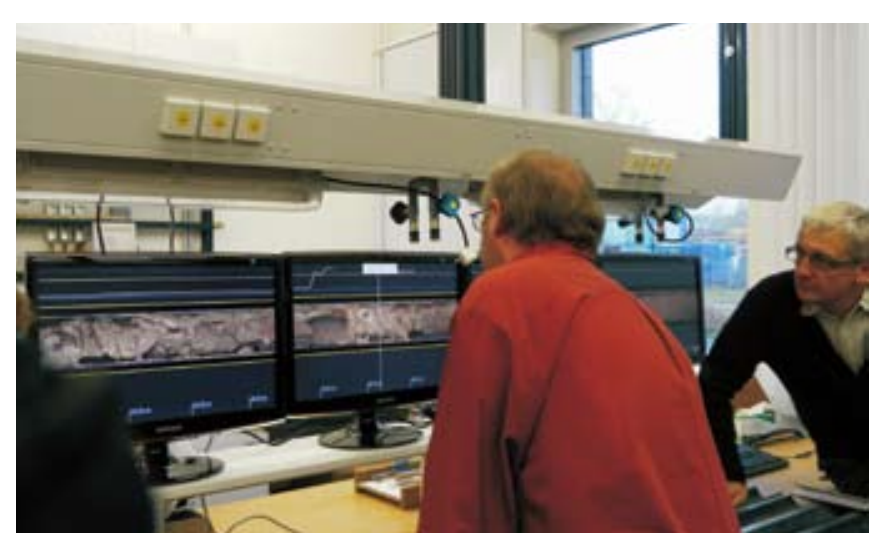

Figure 3. Corelyzer station at the IODP Exp. 313 New Jersey Shallow Shelf onshore science party at MARUM (University of Bremen). This station was fed continuously with scanned images and MSCL data of new core sections as they were added to the ExpeditionDIS. In conjunction with Correlator, this station was used for correlation between sites using lithological features and/or logging data. (Photo by H. Ando, Ibaraki University)

ExpeditionDIS via the Common Exchange Format file. Upon selecting a subset of core sections or all core sections for a drill hole, a non-editable, continuous sequence, scaled to the driller depth, is displayed.

2. By importing a Common Exchange Format file, Corelyzer reads in all core images and corresponding optional logging data (Fig. 2). The utilization of an existing PSICAT plugin will allow visualization of the lithological units graphically beside these scanned images and $\log$ data. The user can add annotations to the images, which are added to the Common Exchange Format file and then exported for use by the other tools.

3. By re-importing the Common Exchange Format data generated by PSICAT, and Corelyzer, the ExpeditionDIS can store all modified or new lithological data.

4. By connecting Correlator, Corelyzer can control visualization and core depth adjustments in runtime using socket commands. It will allow users to utilize rich features in high-resolution core images to generate composite and spliced depth scales. This feature allows more fine-grained interactive stratigraphic correlations.

\section{Benefits and Outlook}

The two test beds demonstrated that the synergetic integration of ExpeditionDIS, PSICAT and Corelyzer is beneficial and enhances the capabilities of the individual stand-alone systems. The ExpeditionDIS and its relational database provide the full documentation of all recovered cores and sections including consistent driller depths and the corresponding scanned images in different grades of resolution. Neither PSICAT nor Corelyzer provides any tools to capture these important primary data, but both need these data as input for generating lithological visual core descriptions and visualization of the scanned images of the core sections and related logging data. In conjunction with
Correlator it will be possible to import the depth adjustment tables by ExpeditionDIS using the same Common Exchange Format so that any data can be output on the same composite or spliced depth scales.

Upcoming scientific drilling expeditions of ICDP and ECORD/IODP will provide further test beds for consolidation and development of such features.

\section{Acknowledgements}

This work has been made possible through bilateral memoranda of understanding between ICDP and IODP, ANDRILL, and LacCore as well as the GeoSciNET initiative composed of CoreWall, Geoinformatics for Geochemistry (GfG), System for Earth Sample Registration (SESAR), PaleoStrat, and ICDP.

\section{References}

Conze, R., Wallrabe-Adams, H.J., Graham, C., Krysiak, F., 2007. Joint Data Management on ICDP projects and IODP mission specific platform expeditions. Sci. Drill. 4:32-34. doi:10.2204/ iodp.sd.4.07.2007

\section{Authors}

Ronald Conze, Operational Support Group ICDP, GFZ German Research Centre for Geosciences, Telegrafenberg, D-14473 Potsdam, Germany, e-mail:conze@gfz-potsdam.de. Frank Krysiak, smartcube GmbH Berlin, Puschkinallee 48, D-12435 Berlin, Germany.

Josh Reed, Andrill Science Management Office, 126 Bessey Hall, Lincoln, University of Nebraska-Lincoln, P.O. Box 880851, Loncoln, NE 68588-0341, U.S.A.

Yu-Chung Chen, University of Illinois at Chicago, Electronic Visualization Laboratory, U.S.A.

Hans-Joachim Wallrabe-Adams, MARUM, University of Bremen, Leobener Str., D-28359 Bremen, Germany.

Colin Graham, British Geological Survey Edinburgh, ESO - ECORD Science Operator, Murchison House, West Mains Road, Edinburgh EH9 3LA, Scotland, U.K.

Volker Wennrich, University of Cologne, Institute of Geology and Mineralogy, Zuelpicher Str. 49a, D-50674 Koeln, Germany.

\section{Related Web Links}

http://www.icdp-online.org

http://www.iodp.org

http://www.ecord.org

http://www.andrill.org

http://1rc.geo.umn.edu

http://www.corewall.org

http://www.geoinfogeochem.org

http://www.geosamples.org

http://www.scientificdrilling.org

http://www.smartcube.de

http://www.wdc-mare.org 